\title{
Research \\ Respect for Grizzly Bears: an Aboriginal Approach for Co-existence and Resilience
}

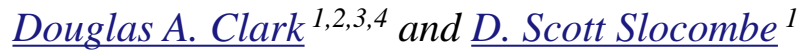

\begin{abstract}
Aboriginal peoples' respect for grizzly bear (Ursus arctos) is widely acknowledged, but rarely explored, in wildlife management discourse in northern Canada. Practices of respect expressed toward bears were observed and grouped into four categories: terminology, stories, reciprocity, and ritual. In the southwest Yukon, practices in all four categories form a coherent qualitative resource management system that may enhance the resilience of the bear-human system as a whole. This system also demonstrates the possibility of a previously unrecognized human role in maintaining productive riparian ecosystems and salmon runs, potentially providing a range of valued social-ecological outcomes. Practices of respect hold promise for new strategies to manage bear-human interactions, but such successful systems may be irreducibly small scale and place based.
\end{abstract}

Key Words: bear ceremonialism; Champagne and Aishihik First Nations; Inuit; Inuvialuit; Northwest Territories; Nunavut; resilience; salmon; social-ecological system; Southern Tutchone; traditional ecological knowledge; Ursus arctos; Yukon

\section{INTRODUCTION}

All I know is respect for bear. When I meet up a bear face to face in the bush, we talk to him and he look at us and pretty soon be turning away. We tell him we live on our own, this is my trail I travel on, for some day for myself. And you do the same out there where you make your living, you can just go 'round there. Make your own living. Look at him for a little while he'll go away. But if they charge us, then we will got no choice but shooting him... we don't shoot him for fun or anything like that. Champagne and Aishihik First Nations Elder, 19 July 2004.

During nearly any public or private conversation about the grizzly bear (Ursus arctos) in northern Canada, someone states that they respect bears or emphasizes the importance of having such respect for them. In such conversations, as well as at more organized venues such as community meetings and workshops on wildlife, the term "respect" is often explicitly acknowledged as a point of agreement between Aboriginal and nonaboriginal cultures about how bears, and indeed other species, ought to be treated. Nevertheless, the term's possible interpretations by these different groups are rarely explored in detail (e.g., LegendSeekers 2002). Such exploration is important because clear communication between Aboriginal and nonaboriginal people is necessary for a variety of civic endeavours, including co-management of wildlife in the Canadian North.

Specifically, the ubiquity of "respect" may lead to simplistic and inaccurate assumptions about what people really mean when they make such statements, masking more fundamental intercultural disagreements about values and preferences (Morrow and Hensel 1992, Natcher et al. 2005). Signs exist that interpretations of respect do in fact differ: Aboriginal people express concerns that common research techniques such as capturing and radio-collaring bears and removing DNA, teeth, or tissue samples are deeply disrespectful and may even make handled bears more dangerous (Loon and Georgette 1989, McDonald et al. 1997, Nadasdy 2003), despite protestations from scientists otherwise and arguments that they are doing such things in the interests of the bears (Van Daele et al. 2001). 
Recent literature documents a historical trend over much of the 20th century in northern Canada toward the external control and marginalization of Aboriginal concerns in wildlife management, as well as giving privilege to scientifically derived information and policies over traditional knowledge and indigenous management practices (Nadasdy 2003, Kulchyski and Tester 2007, Sandlos 2007). This trend has been at least partially reversed over the past three decades through the settlement of Aboriginal land claims, creating co-management institutions for natural resources and wildlife species (Freeman and Carbyn 1988, Treseder et al. 1999). Although the nature of the changes in management practices brought about by land claims settlements has been questioned, the degree of the resulting change to governance as a whole is profound (e.g., Nadasdy 2003, Natcher et al. 2005, White 2006). By contrast, Alaskan wildlife is managed by a combination of state and federal agencies, with fewer co-management institutions (Kofinas 2005). Managing wildlife thus remains a subject of intense cross-cultural negotiation across a large region of North America that is both culturally and geographically diverse, and bears are often problematic subjects for such efforts. For example, First Nations' concerns about disrespectful research methods were a substantial contributing factor in the failure of a proposed grizzly bear conservation plan in the southwest Yukon, even though the plan was led by two co-management boards (Clark and Slocombe 2005). Similar concerns have also led to conflicts and lawsuits over brown bear (Ursus arctos) research projects and hunting regulations in Alaska (Loon and Georgette 1989, National Research Council 1997, Van Daele et al. 2001) and over harvest quotas for polar bear (Ursus maritimus) in Nunavut (Tyrrell 2006, Dowsley and Wenzel 2008). Any unexamined multiplicity of meanings about respect for bears, therefore, has considerable potential to cause problems for wildlife co-management systems.

Our aims are to explore what an Aboriginal idea of respect for grizzly bears means in terms of practices "on the land" and to provide one interpretation of it, recognizing that there are doubtlessly alternative interpretations. To begin, we compare the epistemological contexts of respect in Aboriginal and nonaboriginal cultures. We then present observations of four current emic practices of respect: storytelling, terminology, reciprocity, and ritual. Finally, we consider how this set of practices may enhance the resilience of bear-human relationships as a social-ecological system (Berkes and Folke 1998) and discuss some implications for bear management practices.

The significant role of bears in Aboriginal cultures is a recurrent theme in anthropological literature. The classic reference remains Hallowell's (1926) comprehensive survey of bear ceremonialism throughout the circumpolar world. Hallowell (1926) described major themes of linguistic terminology, usually referring to bears indirectly or in honorific terms; hunting methods; and postmortem rituals involving bear carcasses that appear to be common to cultures throughout North America, Asia, and Europe. These practices are applied to all three species of bear found in these regions: grizzly/brown bear, polar bear, and American black bear (Ursus americanus). Bears in Aboriginal cultures have also been the focus of more contemporary research (Nelson 1969, 1973, Tanner 1979, Shepard and Sanders 1985, Loon and Georgette 1989, Rockwell 1991, Brightman 1993, Black 1995, Georgette 2001, Keith et al. 2005). Taken together, these later studies across a wide geographic range in North America reinforce the general patterns observed by Hallowell (1926), demonstrating numerous commonalities in current and historical practices of diverse Aboriginal groups toward all three North American bear species. Brightman (1993) points out that of all the hunted animals, the bear was the only one capable of turning the tables and hunting man; correspondingly, the practices regarding respect for bears were observed more consistently and elaborately than for important prey such as moose. These practices are judged necessary to maintain the reciprocal and essentially social relationship between hunter and animal prey, upon which both depend. Thus, the widespread use of the term "respect" in this context is hardly new, but there is perhaps greater urgency now to examine what it actually means.

\section{METHODS}

Fifty-nine semi-structured interviews were conducted from 2003 to 2005 with people involved in or affected by grizzly bear management programs in the southwestern Yukon Territory; the Inuvialuit Settlement Region (ISR), Yukon and Northwest Territory; the community of Baker Lake, Nunavut; and west-central Alberta (Fig. 1; Clark 2007). In 2004, we held a series of five focus groups in the southwest Yukon to examine questions about bear 
management in greater detail, working together with the Champagne and Aishihik First Nations (CAFN). First Nation is the preferred term in Canada for both individuals legally recognized as "Indian" and self-governing Aboriginal groups; it is not used to refer to Inuit people (McMillan and Yellowhorn 2004). Focus-group sessions involved CAFN members and nonaboriginal area residents. Interviews and focus groups were recorded, transcribed, and coded using HyperRESEARCH version 2.6 running on Apple OS X. Follow-up visits were made to all study sites between 2005 and 2007 to present and discuss our preliminary results with community members and organizations. Permission was granted by study participants for the use of all quotations.

Several important limitations in our approach to this work must be kept in mind. First, although we drew on data from three northern study sites, the majority of observations came from the southwest Yukon: 89 of 116 bear stories coded were from there. This greater degree of contact may have influenced how we interpreted observations from other study sites. Second, as nonaboriginal researchers, we have probably arrived at our understanding of Aboriginal conceptions and practices of respect for bears through different processes than Aboriginal people have (Nadasdy 2003). Third, there is a fundamental paradox in this research in that a common expression of respect for bears by Aboriginal people involves not talking about them, at least directly (Hallowell 1926, McClellan 2001, LegendSeekers 2002). Our data collection likely was influenced by this custom of limiting what one says about bears, and such influences may not have always been apparent to us.

\section{RESULTS}

\section{Epistemological origins of respect}

Not only do practices regarding bears differ substantially between Aboriginal and nonaboriginal peoples (Fig. 2), but they originate from very different epistemologies. "All things are connected" is a common fundamental theme in the worldviews of indigenous peoples (Berkes et al. 2000, Pierotti and Wildcat 2000, Turner et al. 2000, Atleo 2004, Turner 2005). Atleo (2004) provides a clear window into this worldview through his explanations of a Pacific coastal First Nation's concepts of heshookish tsawalk ("everything is one") and isaak ("respect for all life forms"). Similar themes are echoed in the
Duli, the traditional teachings of the Southern Tutchone. Such a holistic view can be difficult to reconcile with the scientific management approach to gaining knowledge that is predominant in wildlife management agencies (Clark and Rutherford 2005). An additional difference is that western worldviews stress history and the linear flow of time, whereas Aboriginal peoples have quite different notions of time and tend to think more spatially than lineartemporally (Pierotti and Wildcat 2000). One consequence is that Aboriginal knowledge is profoundly contextual and place based, which is quite different from the universalizing tendencies of western scientific and bureaucratic institutions.

Implicit in the holism of Aboriginal cosmologies is the positioning of people on an equal level with all other forms of creation, including bears. From such a perspective, there is no difference between bears and people: bears and other animals are nonhuman persons. In the distant past, living beings switched between animal and human forms; therefore, humans' interactions with animals are essentially social interactions (Brightman 1993, Salmón 2000). The practices involved in maintaining appropriate interactions are guided and informed by the principles of these holistic worldviews. Salmón (2000) describes such an approach as kincentric ecology.

In sharp contrast, most wildlife management practices are based on the idea of discrete populations, rather than individual animals, as units of quantitative analysis (Caughley and Sinclair 1994). However, important and relevant exceptions include some ethological research methods (Krebs and Davies 1991) and the management of wildlifehuman conflicts (e.g., Bath and Enck 2003). This mismatch in epistemological scales is a considerable obstacle for scientifically trained wildlife managers who attempt to understand Aboriginal perspectives because it implicitly devalues the focus on individual animals. In contrast, Aboriginal people seem to have little difficulty in understanding how scientists attempt to see the world, though they may express some skepticism of that perspective:

But how do you guys know; I mean, how do they know all this? They sit and fly around in a helicopter and sit down in front of doing paperwork. How do they know? They never go out on the land and see... (participant of focus group 2). 
Fig. 1. Location of the study sites (indicated by red lettering) in relation to other communities and geographical features in northern Canada.

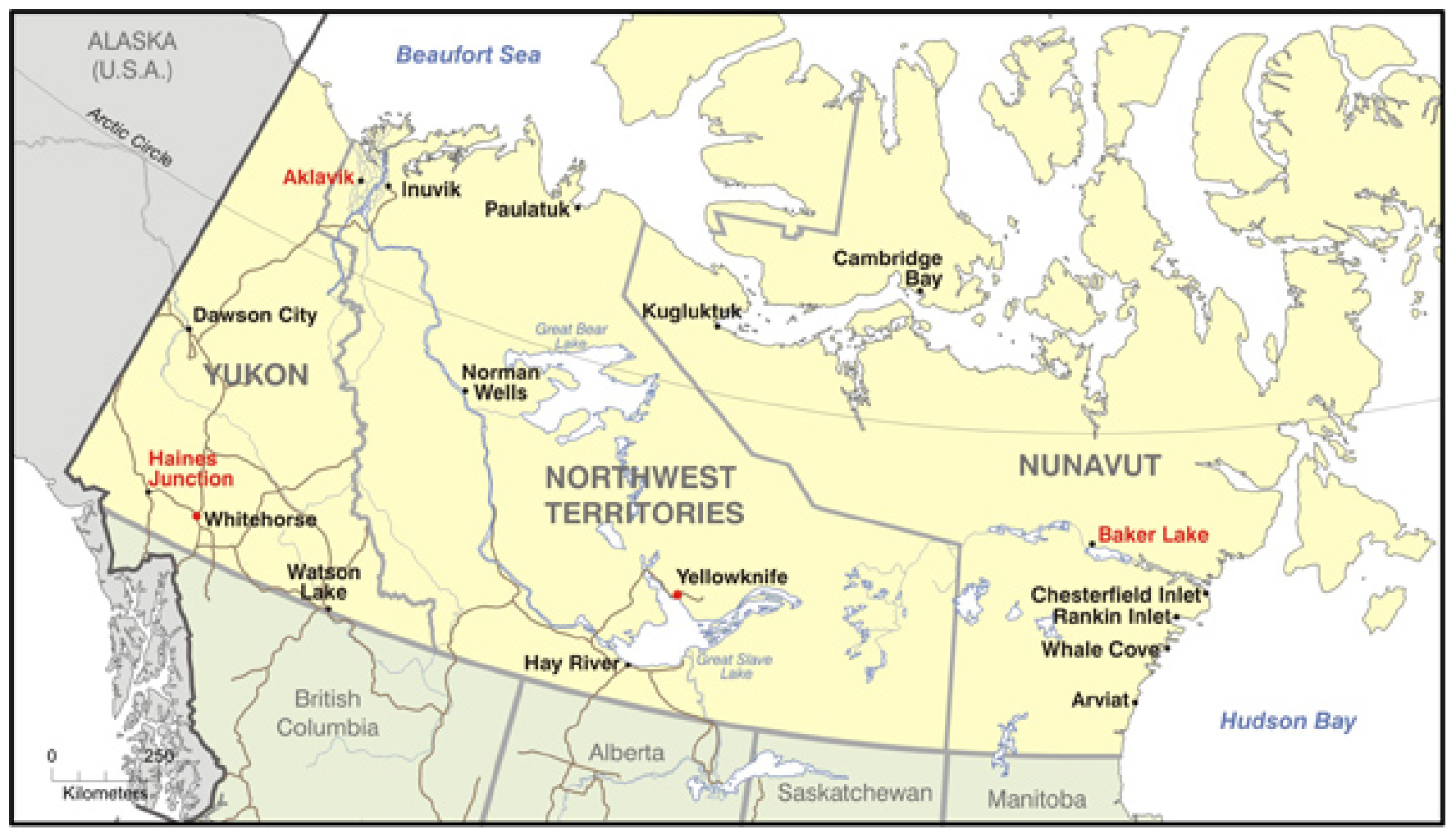

There is little common ground between Aboriginal and Euro-Canadian ideas about respect for bears, and much of that common ground is about negative effects (Fig. 2). Both cultures recognize the risks that bears can pose to human livelihoods and safety, although Aboriginal cultures probably pay greater attention to the additional dimensions of spiritual risk from interacting with such powerful beings (Nelson 1973, McClellan 2001). More optimistically, there may be some correspondence between western ideas of holism and intrinsic value and Aboriginal concepts such as isaak. Intriguingly, this broad philosophical principle resurfaces in Hallowell's unpublished manuscript Bear Ceremonialism in the Northern Hemisphere: Re-examined (American Philosophical Society, Philadelphia, Pennsylvania, USA, 1968). Thirty-eight years after his initial work on the subject, Hallowell acknowledged the parity that Aboriginal cultures see between man and bear as parts of the larger totality of the natural world:
"Man and animals, instead of being separate categories of being, are deeply rooted in a world of nature that is unified."

\section{Practices of respect for bears}

\section{Stories}

It is difficult to overstate the cultural importance of stories as information carriers to Aboriginal peoples, particularly in the southwest Yukon. Bear stories are a common form of narrative storytelling throughout the north, among both Aboriginal and nonaboriginal community members. This was noted by McClellan (2001) and was amply reinforced through the stories told by our study participants in all locations. One story in particular, The Girl Who Married the Bear, is a dramatic and significant story for the First Nations people of the southwest Yukon, 
Fig. 2. Observed aspects of respect for bears in Aboriginal and nonaboriginal North American cultures.

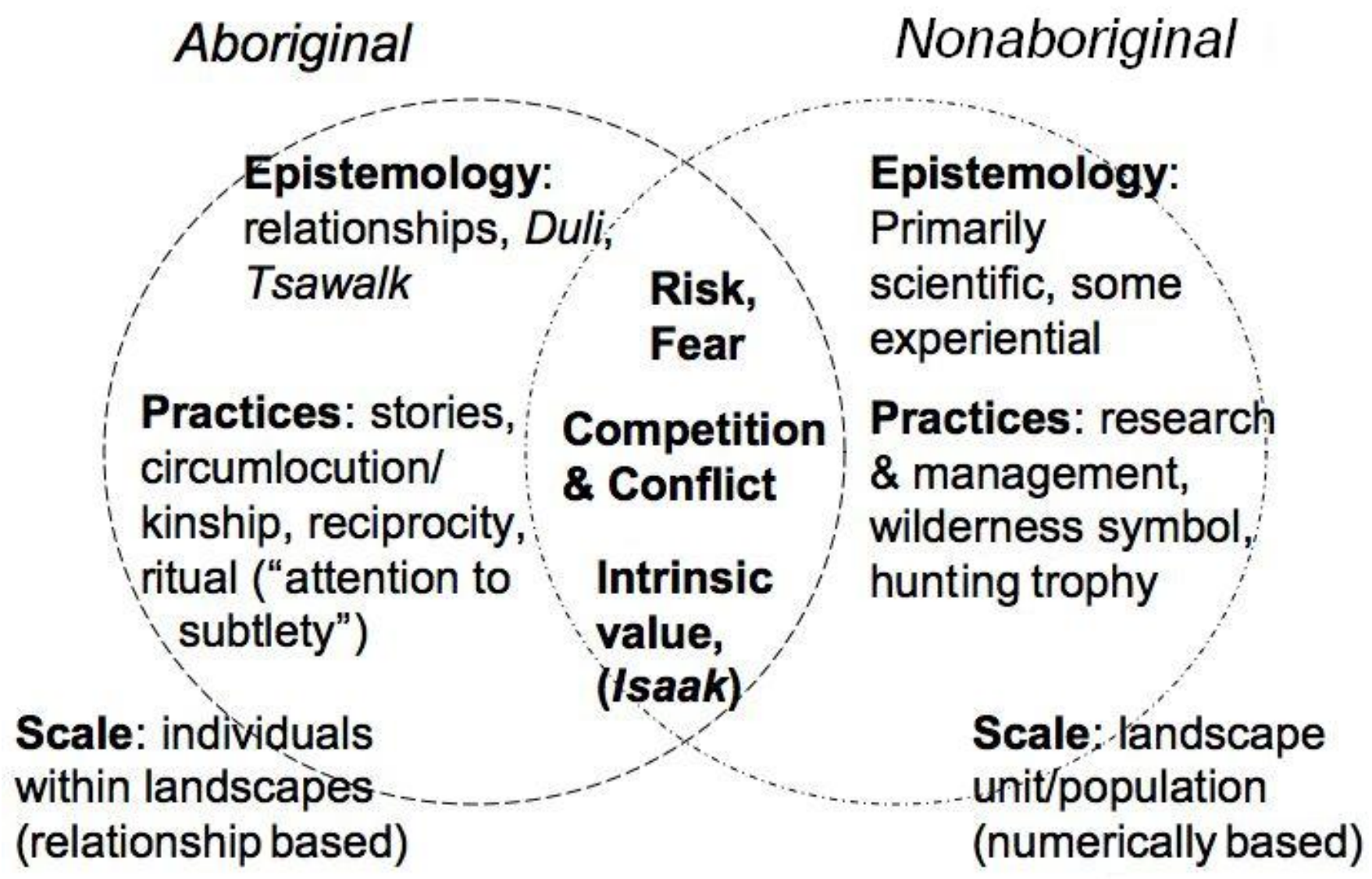

numerous versions of which were recorded and commented on in detail by McClellan (1970). Versions of this story are widespread in Athapaskan and Algonkian cultures (Brightman 1993), as well as among the Tlingit (Wolfe 2006). Although the story varies slightly from teller to teller, the central themes of a young woman's conflicting loyalties to her family and to her new ursine husband, and the consequences of transgressing social rules toward animals, remain the central features. Versions of the story also encode strikingly detailed information about bear ecology, especially denning behavior and den site selection, and hunting, as well as the specific rituals to be observed when a bear is killed
(McClellan 1970). As was explained during a focus group, this story is the primary means by which the Southern Tutchone people pass on their respect for animals to younger generations, ensuring the continuity of their practices.

Two different kinds of stories are apparent in the discourse about bears. The first are the formalized myths, like The Girl Who Married the Bear, which are categorized in the southwest Yukon as an "oldtime story" (McClellan 2001). The other is the "true story," which involves people who are still living or have recently passed away. Such true stories about bears are based on individual peoples' 
experiences, both firsthand experiences and noteworthy events that involved others. Bearhuman conflicts are common themes in such stories; these narratives in particular often include considerable detail about geographical, social, and ecological context and the behavior of bears and people during the actual encounter, as well as causative explanations about why the conflict occurred. For example, many stories of bear-human conflicts described the presence of bear attractants such as fish, game meat, or untidy camps; nutritionally stressed bears in poor physical condition; or situations in which bears were surprised. All are recognized causes of such conflict (Herrero 2002).

Imparting knowledge to youth was considered extremely important by focus group participants. Because bear stories are often dramatic and entertaining, they may be particularly well suited for such a teaching role. Despite this attraction, and perhaps even because of it, there is obvious adaptive significance to both old-time stories and true stories about bears. By describing specific practices for interacting with bears, particularly in conflict situations in which the stakes could be high, listeners would be better equipped to handle such situations themselves. By being told specific information about bear ecology and behavior, aspiring young bear hunters in the audience would be more likely to be successful. Underlying such situational responses, though, is the cultivation among young listeners in particular of a cautious and humble mindset for dealing with bears. A certain measure of fear about bears can be useful as long as it does not lead to inappropriate responses, and one CAFN interviewee told me that fear about bears is deliberately encouraged by the parents of young children. Interestingly, he also said that the only other subject that parents refer to in the same way is rivers. In the steep, glaciated mountains of the southwest Yukon, rivers are cold and fast and their levels fluctuate widely. In terms of objective hazards in that landscape, rivers are likely even more dangerous than bears, so it is not surprising that they are treated similarly.

\section{Terminology: circumlocution and kinship}

There are two interrelated ways of speaking about bears that can be considered practices of respect. The first is to avoid speaking about them directly, that is, to avoid saying "bear" in English or any Aboriginal languages and not saying anything that implies human superiority over bears. The second is to use some form of circumlocution in place of "bear," often an honorific term denoting some form of kinship. These terminologies were widely observed by Hallowell (1926), and both are still very much in use. One CAFN elder carefully explained how he uses the phrase "Big Grandpa" when he speaks about bears; another CAFN member referred to bears as "our brother."

Whichever terminology people use, the usual and very pragmatic justification for speaking respectfully about bears is that they can hear what people say and will respond. In Baker Lake, several Inuit interviewees stressed that one should never wish to see a bear, and that out on the land, one should not speak about them. One of these interviewees talked about traveling on the land with a younger person who wished aloud to see a bear. The older hunter said that one should never wish that because elders had told him that big animals hear and will come. The next day, two grizzlies came, and one even approached the younger hunter quite closely before being chased off. Regardless of one's beliefs, bear hunting can be a dangerous and uncertain proposition and was especially so before firearms became common. In such situations, an attitude of humility and caution, which is what these practices encourage, would be useful and at times perhaps even life saving.

\section{Reciprocity}

In Aboriginal worldviews, reciprocity is at the heart of maintaining appropriate relationships with elements of the natural world, including both animals and humans. Appropriate human-animal relationships are based on reciprocity: animals give themselves to hunters, who must reciprocate with appropriate behaviours or else they risk offending that animal, which will not offer itself again (Tanner 1979, Brightman 1993). Because people and bears can be dangerous to each other, a very basic form of reciprocity is to leave each other alone. This was a key guiding principle mentioned by numerous study participants: "he don't bother me; I don't bother him" (participant of focus group 1). It was repeatedly emphasized that Aboriginal people would not hesitate to shoot a bear if it bothered them, but that they would never shoot bears indiscriminately. Shooting bears can be difficult and hazardous, and participants in one focus group emphasized that one needed to shoot them well and shoot them quickly, a task that not just anyone could 
do. Dogs were considered effective at detecting and deterring bears, as long as they were well trained and experienced with bears.

To assist bears and people to avoid bothering each other, one could use "bear medicine." This medicine consists of special Southern Tutchone words that one can say for safe passage when a bear is encountered on the trail. During one focus group, there was considerable discussion about which of the community members might or might not possess bear medicine. Apparently, bear medicine can be purchased, although it was not made clear how one might go about seeking to buy it or what payment might be appropriate. Interestingly, scientists and bear managers also advise people involved in surprise encounters with bears to speak calmly to the bear (Herrero 2002). Extending this comparison, the proliferation of such advice in the form of books and media on safety in bear country (e.g., Shelton 1994, Cheek 1997, Herrero 2002, Stringham and Fredrikkson 2007) has clear parallels to spoken bear medicine.

A clearly reciprocal practice involves the interaction of people and bears during salmon runs in the Tatshenshini River system of southwest Yukon. Salmon are an important food resource for CAFN people (O'Leary 1992) and they compose 39\% of the diet of grizzly bear in this area (Mowat and Heard 2006). Despite such obviously high potential for competition, sharing the river with bears was discussed in two focus groups and by several interviewees; it appears to be a traditional practice that some CAFN members still adhere to:

...everybody left the river by the afternoon 'cause the morning was the people time and the afternoon and evening was the bear's turn to fish... (participant of focus group 2)

Another practice from the salmon streams involves the idea of a "good bear." At Klukshu Village, a long-used CAFN salmon-fishing site, older male or female bears that fished close to the village were left alone or possibly even encouraged to remain. These bears kept away the younger bears that cause the majority of the conflicts with people. This practice obviously required considerable discipline among community members and reflects a sophisticated, experience-based understanding of grizzly bear behavior. The grizzly bear, like other bear species, exhibits a clear dominance hierarchy, and subadults, which is the age class that is disproportionately involved in bear-human conflicts, are at the bottom (Mattson 1990). An older bear that was experienced with people, in a setting with abundant food resources and likely a relatively high density of bears, would probably develop a relatively short overt reaction distance and might even habituate to people (Herrero et al. 2005, Smith et al. 2005). Such a bear would be relatively less risky to be around and would be an effective deterrent for wandering subadult bears. Unfortunately, this system seems to have broken down in recent decades. Some speculate that this is because the Klukshu area has become a release site for problem bears that are captured and relocated from elsewhere. However, it may also reflect a persistent overharvest of grizzlies in the region (Maraj 2007), which could theoretically make older bears, especially males, relatively more scarce and encourage subadult immigration (Taylor 1994, Swenson et al. 1997).

A similar practice of respect for bears apparently happens during moose hunts in the southwest Yukon. The large quantity of meat on a moose means that hunters often cannot pack it all out in one trip, even using all-terrain vehicles. Grizzlies have been known to claim hunter-killed moose carcasses in the Yukon. Consequently, hunters are very careful when returning to kill sites. One focus group participant offered this story about such a return:

I was ... coming up with the four-wheeler to haul the meat out ... Anyhow, there was a grizzly watching them from the bank down and... I hollered to them "there's a bear just above you guys." ... And ah, so I shouted and it, the bear kind of moved away, and we finished skinning it [the moose] out. But by that time, it was getting dark, so we only had enough time to get one load out. And when we were going back to camp ... the young guy asked me, he said, "Do you think the bear is going to bother the meat?" and I said, "I don't know," I said, "but I respect the bear," and I said I asked him not to bother it. But we put the moose, the meat, we put on a tarp and we put a hide over it and threw the head on top. And so we went back out the next morning to pick up the meat, and the bear had come down to the kill site, and he drug the gut pile around and he got the head, but he just left the rest of the meat, never touched it. ... I told that 
young guy "You got to have to thank that bear for not bothering your meat." So we cut off a big part ... and we left it on a big rock there for him, and that same weekend there was another person that was hunting up in Lucky Camp. They shot a moose too, that same weekend, the same time we shot this other moose, and that bear took over their kill site ... and it was laying on top waiting, to protect the meat I guess. The guys that had come up there had to shoot the bear. So what is the difference ... how come the bear left us alone, but went after somebody else? And my thinking is that it was because of my belief in the bear and asking, talking to the bear, asking him not to bother it, and I don't think the other persons had those kinds of beliefs. (participant of focus group 1).

\section{Rituals}

Although Hallowell (1926) described post-mortem rituals performed on bears, these were not discussed by study participants in any detail, although some mentioned that there were such rituals and described them in very vague terms. People usually said they had never seen such rituals personally or that they had been largely forgotten. Nevertheless, one interviewee talked about having performed these rituals recently, after a younger relative of his had shot a bear and then telephoned him seeking guidance. Because such spiritual matters are considered very private, we did not press our inquiries on this topic.

Nonetheless, some observations suggest other ritual practices. For example, black bear is commonly eaten in the southwest Yukon, but focus group participants observed that there is apparently a taboo against eating grizzly bear meat; this was also mentioned by several authors (McClellan 1970, 2001, Rockwell 1991). Such food taboos may be highly localized or even individualized, as Nadasdy (2003), who worked with the neighbouring Kluane First Nation (also Southern Tutchone people), observed none. The Girl Who Married the Bear may also explain the species specificity of the taboo on bear meat because the bear husband was a grizzly, and one outcome of the story is that after the marriage, grizzly bear became "half-human." No participants mentioned whether this particular taboo applied to just women, as noted by McClellan (2001).
Both the Inuvialuit and the related Alaskan Inupiat remove the hyoid bone from the throat of a slain bear to ensure that the bear's spirit will not remain angry with the hunter and endanger him in the future (Loon and Georgette 1989, MacHutchon 1996, Jans 2005). Although these sources offer no explanation of why this practice might have such an effect, one potential explanation is offered in The Girl Who Married the Bear, although the geographic locus of that story is far south, and contemporary Southern Tutchone hunters apparently do not remove the hyoid. Nevertheless, in two of the versions recorded by (McClellan 1970: versions 1a and 1b), the storyteller locates and describes the hyoid bone quite precisely, referring to it as the "arrowhead" of the human brothers who finally shoot arrows into their sister, who had become a bear, and break the peace between bears and humans. It is not difficult to conceive of the removal of these arrowheads as a symbolic restoration of that peace. Indeed, some tellers of the story (McClellan 1970: versions 6 and 7) draw a direct connection between the postmortem rituals performed for bears and the k'owakan ("peace hostage," Tlingit) ceremony, which restores peace between two warring sib groups, or clans. Because bears and people are both considered persons, related by clan structures (McClellan 2001), one might think that such a ceremony would be the appropriate way to restore peace. Indeed, McClellan (1970) documents an observation by a Southern Tutchone woman that bears and humans had once held such a peace ceremony.

\section{DISCUSSION}

\section{Respect for bears and the resilience of bear- human systems}

Specific relationships between bears and humans, considered in the context of a shared local environment, can be conceptualized as a linked social-ecological system (Berkes and Folke 1998). Smith (1991) first advanced the idea of the grizzly bear-hunter system, of which the main elements are bears and humans who hunt them. Expanding this concept, most current bear-human systems would include not just bear hunters, but also the ecosystems they inhabit or use, other groups of people, and other social creations such as technology and the institutions that mediate human interactions with bears, e.g., as laws, government departments, parks, and tourism businesses (Fig. 3). The system can be 
considered as holonarchical (Kay et al. 1999) or panarchical (Gunderson and Holling 2002); that is, it is at once both a distinct unit in and of itself, and also an integral part of other social and ecological systems at different scales.

By mapping observed practices of respect in relation to the relationships between such a system's components, it becomes apparent that these practices could play numerous roles in strengthening system linkages, thereby enhancing the resilience of the system as a whole (as in Holling 1973, Gunderson 2000, Carpenter et al. 2001, Gunderson and Holling 2002). Of the four classes of practices, reciprocity influences the most linkages: all six (Fig. 3). Because grizzlies and people are, or traditionally were, dependent on the same resources, e.g., salmon, berries, and ungulates, the potential for conflict is high. Because conflicts can have negative consequences for people and bears, there are obvious benefits to preventing and resolving them. The general practice of leaving each other alone, aided by specific techniques such as bear medicine, would operate on the human-bear linkage, tending to reduce the potential for direct interference competition, injury, or deaths.

The practices of the good bear and of sharing the river have potential for considerable ramifying effects throughout the entire social-ecological system. By modifying their salmon harvesting behaviors to accommodate bears, people affect not only human-ecosystem and human-bear linkages directly, but also the bear-ecosystem linkage, as bears are a significant vector of marine nitrogen into terrestrial forest ecosystems in nearby coastal Alaska (Hilderbrand et al. 1999, 2004, Helfield and Naiman 2002, 2006). This nutrient transfer has been described as a keystone interaction because of the numerous effects on riparian ecosystem structure and function, including enhanced spawning and rearing habitat for salmonids through the provision of large woody debris from enhanced tree growth, which is a positive feedback into the system (Helfield and Naiman 2006). Although there is much spatial and temporal variation in this interaction's significance throughout Alaska and western Canada, and its significance in the southwest Yukon is unknown, practices that enhance this interaction would have obvious social and ecological benefits in terms of increased production of salmon, large trees, and browsing animals such as moose. In Klukshu Creek, the salmon runs are highly pulsed, rather than continuous (O'Leary 1992). Such temporal resource clustering reduces competition (Krebs and Davies 1991) because both bears and humans would be fully occupied in catching salmon at the same time. Such a situation might tend to favor the development of such reciprocal sharing strategies, as opposed to a system in which there was a constant low-level run of fish that humans and bears competed for more directly. Further investigation of bear-salmon-ecosystem-human relationships in the southwest Yukon, and nitrogen transport in particular, is clearly warranted, particularly because the potential role of Aboriginal practices in maintaining such systems has not yet been recognized in the literature.

Access to salmon also increases the fitness and reproductive success of grizzly bear populations compared to those without salmon (Mowat and Heard 2006), raising an important point about these practices. There was not unlimited tolerance for grizzly bear on salmon streams; bears were thinned out at Klukshu when there were "too many." This was usually done in late summer by several men shooting from blinds built in trees, which is apparently a long-standing technique (McClellan 2001). The shooting was done by designated men, at the request of elders, indicating an institutionalized practice. It was a controlled process, with monitoring and sanctioning mechanisms evidently in place, although the nature of these mechanisms is not entirely clear. Nowadays, however, such shooting conflicts with the dominant institutional practices. Even though defence kills of grizzlies are legal in the Yukon, the determination of whether a specific incident constitutes a defence kill is made by law enforcement officials and the courts. The man who currently fulfills the designated shooter role in Klukshu, as did his father before him, complains that the elders still ask him to take care of particular bears, but when he does so, he ends up being charged by the game warden and having to pay the fine.

In all of these practices, people learned about bear and ecosystem behaviors that they observed, but bears must have learned too for any such reciprocal practices to have persisted, particularly those that involve sharing a resource such as salmon or a moose kill. Thus, both human and ursine knowledge bases would be enhanced through reciprocity.

Stories sustain the human knowledge base over time by transmitting information across generations (Fig. 
Fig. 3. Linkages in bear-human systems are influenced by the four different types of practices of respect.

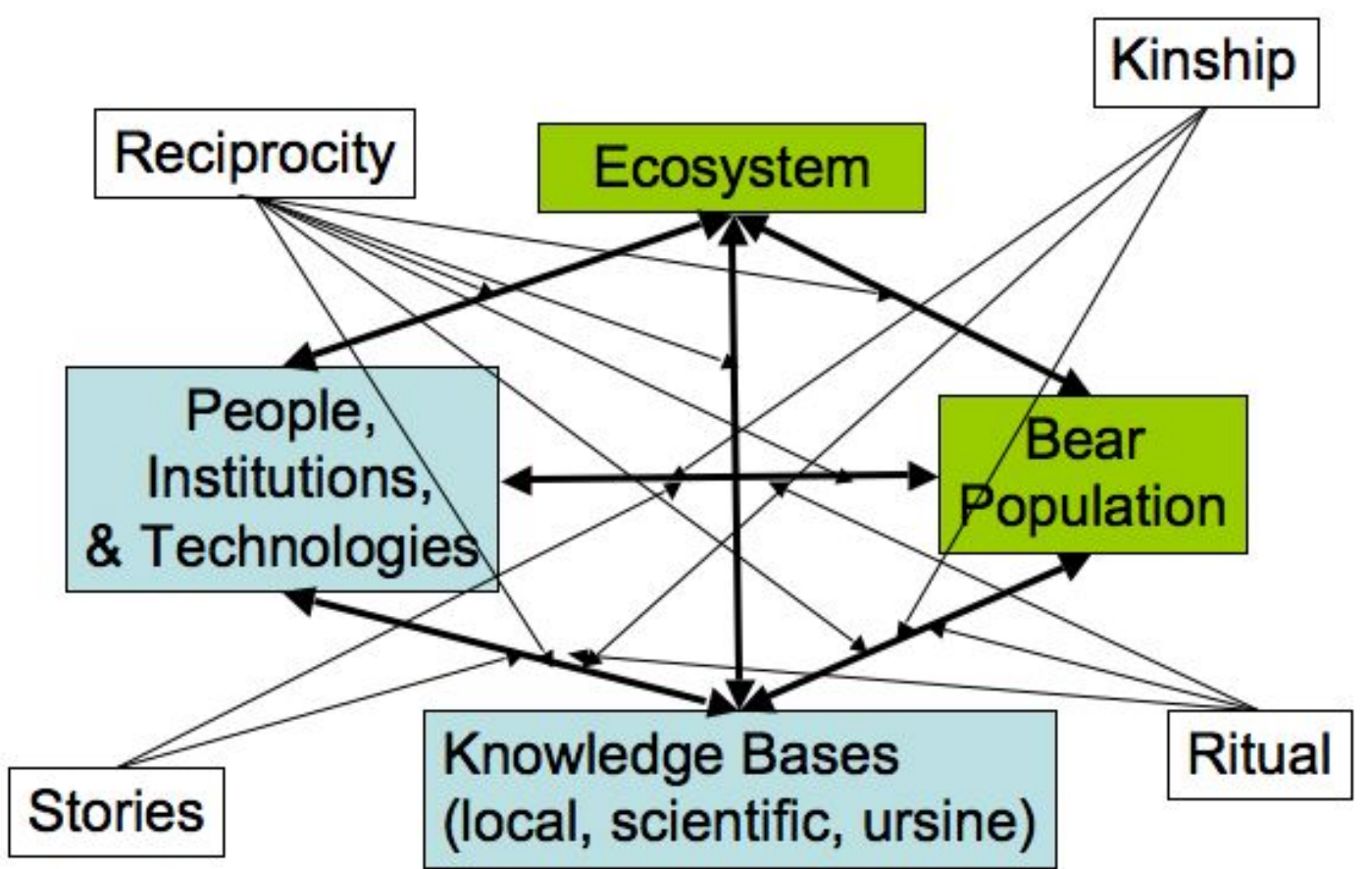

3). Stories about bears encode specific information about their ecology and linkages to the ecosystem, hunting practices, and outcomes of encounters (human-bear linkages) that can later be used by listeners. Stories appear to be the primary means by which the linkages between human knowledge bases and the other components of the system are maintained and kept current and strong. Because oral traditions can readily incorporate new information, they are adaptive in the face of change and can be used to emphasize different messages for specific audiences (Cruikshank 1998). Individual peoples' true stories about bear encounters form a remarkably detailed and flexible knowledge base about the distribution and nature of bear-human encounters in the southwest Yukon. As new situations arise, they become part of that knowledge base, but older stories, particularly those in which people were injured or killed, also remain important. For example, people mentioned grizzly bear maulings from the 1930s, and the 1976 mauling of a woman by a black bear near Dezadeash Lodge was described several times. The adaptive value of incorporating and transmitting such knowledge about situations that the listeners might also encounter is obvious. 
Terminology expresses kinship between humans and bears, and these specific linguistic practices act as the guideposts for the proper ways of navigating that social relationship (Fig. 3). Terminology reinforces a kincentric ecology approach (Salmón 2000), preserving knowledge about appropriate human interrelationships, not just with bears, but also with all other living beings. As such, it touches on the epistemological foundations of practices of respect. One nonaboriginal interviewee who has spent many years conducting traditional knowledge research offered a working definition of how such respect is demonstrated: "attention to subtlety." This working definition was apparently arrived at after much thought and discussion with an anthropologist colleague; recognizing it in practice requires considerable awareness of Aboriginal culture. By continually stressing the social nature of the bear-human relationship, it likely becomes easier to pay sufficient attention to its subtleties and to remember to express it in practice. In pragmatic terms too, speaking about bears using circumlocution and honorifics encourages a cautious, humble approach to the bear-human linkage during bear hunting and other encounters with bears, increasing a hunter's odds of both success and survival.

Rituals primarily act on the bear-human linkage by keeping the peace between people and grizzly bears (Fig. 3). As elsewhere (Tanner 1979, Brightman 1993), the post-mortem rituals related to the $k$ 'owakan ceremony are likely meant to ensure that the slain bear's spirit is not offended and to communicate to other bears that it was treated well. This would make other bears better disposed toward people and more likely to offer themselves to hunters in the future. It is possible that the taboo against eating grizzly meat also has a similar influence on the system, although its fragmented scope may limit its effects. This type of taboo was categorized as a segment taboo by Colding and Folke (2001), who noted that such taboos can have the effect of reducing the take of taboo species. In the southwest Yukon, such a taboo against grizzlies, but not against black bears, would shift hunting effort to the species with the higher reproductive rate (Bunnell and Tait 1980), although it would likely have no effect on the take of either species for other reasons.

\section{Qualitative management of bear-human systems}

Freeman (1999) identified respect and reciprocity as important elements in nonquantitative indigenous resource management systems. The goal of such qualitative management systems is ecosystem resilience, whereas the corresponding goal for quantitative management systems is the extraction of a constant, controlled flow of resources (Holling et al. 1998, Berkes et al. 2000). In qualitative management, environmental feedbacks result in a deliberate change in trajectory of resource use toward greater or lesser exploitation, rather than toward a quantitative yield target (Berkes et al. 2000).

Taken together, the practices of respect described above form a coherent set of strategies that could be considered as a qualitative management system (Holling et al. 1998, Berkes et al. 2000) for grizzly bear in the southwest Yukon. This characterization is well illustrated by the set of practices involving bears on salmon streams. There, bears are tolerated or even encouraged, but their numbers are reduced when there are too many. This practice involves ongoing monitoring of bears, apparently by elders, although the phrase "too many" suggests that the parameter of interest to people may be conflicts or encounter rates or even numbers of bears in a given area, but not necessarily total population levels. Nevertheless, although CAFN people clearly possessed the technology for effective bear killing, using babiche (dried moosehide) snares and deadfall traps before firearms became available, they had no apparent interest in extirpating bears. Ultimately, the local grizzly bear population is or was being managed for a desired state that was assessed in multiple ways, including both the nature and frequency of bear-human interactions, but probably also fishing success and other social-ecological parameters. That sort of desired state would be quite unlikely able to be expressed accurately or meaningfully in quantitative terms, especially because such numerical targets would require constant adjustment over time. In this situation, the resilience of a complex social-ecological system is apparently being maintained by a set of deliberate practices.

Despite the apparent existence of a qualitative management regime, the maintenance of system resilience is not guaranteed. The southwest Yukon's bear-human system is apparently vulnerable to 
cross-scale influences (Berkes et al. 2005) from the larger social-ecological systems in which it is embedded. One major influence of considerable concern to participants is the loss of generational continuity in Aboriginal traditions. Such loss essentially decouples their knowledge base from the ecosystem, rendering it static and reducing its accuracy and utility in changing circumstances, ultimately leaving younger generations less able to cope (Cruikshank 1998). Cross-scale influences may also result from even more specific factors such as regional wildlife harvest policies. During the 1980s and 1990s, grizzly bear hunting regulations were deliberately liberalized in this region to enhance moose calf survival. These measures were apparently not sufficient to result in any measurable change in bear harvest levels, but they would have contributed to long-term regional overharvest (Maraj 2007) that in turn may have contributed to the breakdown of the "good bear" practice at Klukshu.

Importantly, none of the foregoing is to say that such practices mean that a utopian coexistence between Aboriginal peoples and bears was inevitable or even necessarily always desired (Wolfe 2006). For example, there are indications that the range of grizzly bear was constrained by Aboriginal people even prior to European contact. Displacement by Aboriginal people has been identified as a likely cause for the absence of grizzlies from Vancouver Island and areas of the United States east of the Mississippi (Mattson et al. 2005), and has also been suggested for the lower Columbia River (Schullery 2002). Fossil evidence shows that brown bear, which are now absent, were once found on Prince of Wales Island, Alaska (Heaton et al. 1996), and the Haida Gwaii Archipelago, British Columbia (Wigen 2005); both of these are places with a long history of human habitation. Nevertheless, even these potential and unquantified range losses for grizzlies are minor in comparison to those in the two centuries following European settlement (Mattson and Merrill 2002) and likely occurred over a much longer time. This coarse empirical comparison suggests that Aboriginal people were generally more successful at maintaining resilient grizzly bear-human systems in North America than Westernized society has been thus far.

\section{Implications for bear management in practice}

Bear management, as practiced throughout North America, involves an established combination of technological and regulatory efforts to prevent and mitigate conflicts between bears and humans (e.g., Herrero 2002, Wondrak-Biel 2006). Such programs often employ techniques that are regarded as profoundly disrespectful by First Nations people such as capturing and relocating bears (Nadasdy 2003, Wolfe 2006, Clark 2007). These activities are justified by appeals to benefits such as human safety, bear conservation, and, increasingly, reducing liability risk to management agencies (LaMorte 2001). Nevertheless, the inherent uncontrollability of grizzlies due to their strength, temperament, and wide-ranging habits makes them poor subjects for any form of command-and-control management except outright extirpation. Given that, the use of the term "co-existence" by participants in two different focus groups indicates a pragmatic, common-sense perspective and marks an important break with the very idea of managing bears:

\section{I keep saying ... that you co-exist with grizzly bears. You don't try and manage them, and when you look at even grizzly bear management plans ... it's not management, it's somebody's theory on grizzly bears... (Participant of focus group 2).}

Clearly, Aboriginal and scientific worldviews are far apart when it comes to comprehensively defining appropriate human behavior toward bears, but the barriers between them may be linguistic, as well as cultural. Much of the wildlife management discourse in the north, and all of it in the southwest Yukon, is conducted in English. This reality strongly limits the expression of Aboriginal knowledge, perspectives, and practices within that discourse (Brody 1988), as does the equally fundamental challenge of reconciling Aboriginal and nonaboriginal epistemologies, including science (Natcher et al. 2005, Huntington et al.2006).

More subtly, a unilingual, but bicultural, discourse also encourages the problematic assumption, at least among nonaboriginal participants, that everyone means the same thing when they use the same word. This very much seems to be the case with the word "respect," as applied to bears. The danger of such assumptions is that when wildlife managers compare their own idea of respect with what they observe, a cognitive dissonance emerges that could 
eventually lead to accusations of hypocrisy and dismissal of Aboriginal perspectives that do not conform to their own. Three of my interviewees, all of who were territorial or federal government wildlife managers, expressed to me considerable frustration at their inability to reconcile statements by Aboriginal people about respecting bears with their own observations. To them, Aboriginal people often appeared deeply afraid of bears, took few precautions to minimize bear attractants such as garbage or carcasses around their camps, and were quick to shoot bears that ventured into the camps. From their institutional perspective, steeped in scientific rationality and the ethos of the wildlife management profession, such behavior led to what they felt were unnecessary deaths of bears and was far from respectful. Without a compelling alternative explanation, these managers may very well find themselves hardening their own standpoints and dismissing others. The damage such outcomes could do to the functioning of wildlife comanagement regimes is considerable.

Bear-human systems are dynamic. Learning does take place within them and, where unconstrained by asymmetrical power relationships, new technologies (e.g., cracker shells) and science-based approaches (e.g., quotas) are selectively adopted in circumstances in which they are perceived to be useful (Clark 2007). Further understanding of how learning and adaptation occur in such systems, particularly in terms of their adaptation to socialecological change, would be particularly important. Knowing more about the dynamics of bear-human systems would become critical if attempts are ever made to apply these or similar practices elsewhere. There may be real limits to the utility of specific practices in locations other than where they originated, especially if they are applied out of their original social-ecological context. For example, applying the "good bear" idea to an unregulated, highly used salmon stream has obvious potential for negative consequences for both people and bears, especially during a year when the run is poor. Research from Yellowstone National Park also indicates that caution is warranted; grizzly bear that forage near people are significantly more likely to be involved in conflicts with park visitors and end up being destroyed (Mattson et al. 1992). Individual peoples' behavior and institutional context may therefore be some of the more important factors limiting the potential extension of such practices to other situations.
The related question of whether such local-scale indigenous management systems can be scaled up and applied across a larger area remains open (Ostrom et al. 1999, Berkes 2006). In the case of grizzly bear-human systems, which appear to be dependent on extensive and detailed place-specific knowledge, plus much individual restraint, the likelihood of successful scaling up is probably not very high. This may be especially so for the extensive set of practices involving reciprocity and salmon. All of the known present and historic Aboriginal salmon fishing activities in the Tatshenshini River system occur on small, clearwater side streams (O'Leary 1992), which suggests that the bear-human systems that are operative in such places might be irreducibly small scale and place based. The adaptation of respect-based approaches for bear-human coexistence should be approached carefully, with humble expectations, and while paying considerable attention to the social-ecological context of such endeavours.

Responses to this article can be read online at: http://www.ecologyandsociety.org/voll4/iss 1/art42/ responses/

\section{Acknowledgments:}

Financial support for this research was provided by The Canon National Parks Science Scholars Program, the Social Sciences and Humanities Research Council of Canada, Wilfrid Laurier University, Mountain Equipment Co-op Environment Fund, the Northern Scientific Training Program of the Canadian Department of Indian Affairs and Northern Development, TransCanada Pipelines Graduate Award, Yukon College Northern Research Institute, Aurora Research Institute, and Alberta Conservation Association. Linaya Workman, Renewable Resources Manager for the Champagne and Aishihik First Nations, and her family, especially her father Richard Hume, helped us to begin to understand First Nations' cultural perspectives on bears, salmon, and the land. Lyn Hartley professionally facilitated our focus groups in 2004. Inuktitut translation was provided be Betsy Aksawnee, Sally Ikuutaq, and Hattie and Tom Mannik, of Baker Lake. We are grateful to all of the study participants who shared so freely, as well as to our student transcribers and the many other people and organizations who supported this work. 
The development of our ideas advanced significantly during conversations with Julie Cruikshank, Midori Nicholson, and Barney Smith. Figure 1 was produced by Pam Schaus, Cartographer at the Department of Geography and Environmental Studies, Wilfrid Laurier University.

\section{LITERATURE CITED}

Atleo, E. R. 2004. Tsawalk: a Nuu-chah-nulth worldview. University of British Columbia Press, Vancouver, Canada.

Bath, A. J., and J. W. Enck. 2003. Wildlife-human interactions in National Parks in Canada and the USA. Social Science Research Review 4(1):1-32.

Berkes, F. 2006. From community-based resource management to complex systems: the scale issue and marine commons. Ecology and Society 11(1): 45. [online] URL: http://www.ecologyandsociety.org/ vol11/iss 1/art45/.

Berkes, F., N. Bankes, M. Marschke, D. Armitage, and D. Clark. 2005. Cross-scale institutions and building resilience in the Canadian North. Pages 225-247 in F. Berkes, R. Huebert, H. Fast, M. Manseau, and A. Diduck, editors. Breaking ice: renewable resource and ocean management in the Canadian north. University of Calgary Press, Calgary, Canada.

Berkes, F., J. Colding, and C. Folke. 2000. Rediscovery of traditional ecological knowledge as adaptive management. Ecological Applications 10 (5):1251-1262.

Berkes, F., and C. Folke, editors. 1998. Linking social and ecological systems: management practices and social mechanisms for building resilience. Cambridge University Press, Cambridge, UK.

Black, L. T. 1995. Bear in human imagination and in ritual. Ursus 10:343-347.

Brightman, R. A. 1993. Grateful prey: Rock Cree human-animal relationships. University of California Press, Berkeley, California, USA.

Brody, H. 1988. Maps and dreams: Indians and the
British Columbia frontier. Douglas \& McIntyre, Vancouver, Canada.

Bunnell, F. L., and D. E. N. Tait. 1980. Bears in models and in reality-implications to management. International Conference on Bear Research and Management 4:15-23.

Carpenter, S., B. Walker, J. M. Anderies, and N. Abel. 2001. From metaphor to measurement: resilience of what to what? Ecosystems 4 (8):765-781.

Caughley, G., and A. R. E. Sinclair. 1994. Wildlife ecology and management. Blackwell, Oxford, UK.

Cheek, R. 1997. Learning to talk bear: so bears can listen. Skyline Publishing, Columbia Falls, Montana, USA.

Clark, D. 2007. Local and regional-scale societal dynamics in grizzly bear conservation. Dissertation. Wilfrid Laurier University, Waterloo, Canada.

Clark, D., and D. S. Slocombe. 2005. Renegotiating science in protected areas: grizzly bear conservation in the southwest Yukon. Pages 33-53 in G. Humphrys and M. Williams, editors. Presenting and representing environments. Springer, Dordrecht, The Netherlands.

Clark, T. W., and M. B. Rutherford. 2005. The institutional system of wildlife management: making it more effective. Pages 211-253 in T. W. Clark, M. B. Rutherford, and D. Casey, editors. Coexisting with large carnivores: lessons from greater Yellowstone. Island Press, Washington, D. C., USA.

Colding, J., and C. Folke. 2001. Social taboos: "invisible" systems of local resource management and biological conservation. Ecological Applications 11(2):584-600.

Cruikshank, J. 1998. The social life of stories: narrative and knowledge in the Yukon Territory. University of Nebraska Press, Lincoln, Nebraska, USA.

Dowsley, M., and G. Wenzel. 2008. "The time of the most polar bears": a co-management conflict in Nunavut. Arctic 61(2):177-189.

Freeman, M. M. R. 1999. Respect and reciprocity 
as key elements in Arctic sustainable use strategies. Pages 89-99 in J. Oglethorpe, editor. Tenure and sustainable use. IUCN, Gland, Switzerland.

Freeman, M. M. R., and L. N. Carbyn, editors. 1988. Traditional knowledge and renewable resource management in northern regions. IUCN and Boreal Institute for Northern Studies, Edmonton, Canada.

Georgette, S. 2001. Brown bears on the northern Seward Peninsula, Alaska: traditional knowledge and subsistence uses in Deering and Shishmaref. Technical Paper Number 248. Alaska Department of Fish and Game, Juneau, Alaska, USA. Available online at: http://www.subsistence.adfg.state.ak.us/ TechPap/tp248.pdf.

Gunderson, L. H. 2000. Ecological resilience-in theory and application. Annual Review of Ecology and Systematics 31:425-439.

Gunderson, L. H., and C. S. Holling, editors. 2002. Panarchy: understanding transformations in human and natural systems. Island Press, Washington, D.C., USA.

Hallowell, A. I. 1926. Bear ceremonialism in the northern hemisphere. American Anthropologist 28 (1):1-175.

Heaton, T. H., S. L. Talbot, and G. F. Shields. 1996. An ice age refugium for large mammals in the Alexander Archipelago, southeastern Alaska. Quaternary Research 46(2): 186-192.

Helfield, J. M., and R. J. Naiman. 2002. Salmon and alder as nitrogen sources to riparian forests in a boreal Alaskan watershed. Oecologia 133 (4):573-582.

Helfield, J. M., and R. J. Naiman. 2006. Keystone interactions: salmon and bear in riparian forests of Alaska. Ecosystems 9(2):167-180.

Herrero, S. 2002. Bear attacks: their causes and avoidance. Revised edition. Lyons Press, Guildford, Connecticut, USA.

Herrero, S., T.Smith, T. D. DeBruyn, K. Gunther, and C. A. Matt. 2005. Brown bear habituation to people - safety, risks, and benefits. Wildlife Society Bulletin 33(1):362-373.
Hilderbrand, G. V., S. D. Farley, C. C. Schwartz, and C. T. Robbins. 2004. Importance of salmon to wildlife: implications for integrated management. Ursus 15(1):1-9.

Hilderbrand, G. V., T. A. Hanley, C. T. Robbins, and C. C. Schwartz. 1999. Role of brown bears (Ursus arctos) in the flow of marine nitrogen into a terrestrial ecosystem. Oecologia 121(4):546-550.

Holling, C. S. 1973. Resilience and stability of ecological systems. Annual Review of Ecology and Systematics 4:1-23.

Holling, C. S., F. Berkes, and C. Folke. 1998. Science, sustainability, and resource management. Pages 342-362 in F. Berkes and C. Folke, editors. Linking social and ecological systems: management practices and social mechanisms for building resilience. Cambridge University Press, Cambridge, UK.

Huntington, H. P., S. F. Trainor, D. C. Natcher, O. H. Huntington, L. DeWilde, and F. S. Chapin III. 2006. The significance of context in community-based research: understanding discussions about wildfire in Huslia, Alaska. Ecology and Society 11(1): 40. [online] URL: http://www.ecolog yandsociety.org/vol11/iss1/art40/.

Jans, N. 2005. The grizzly maze: Timothy Treadwell's fatal obsession with Alaskan bears. Dutton, New York, New York, USA.

Kay, J. J., H. A. Regier, M. Boyle, and G. Francis. 1999. An ecosystem approach for sustainability: addressing the challenge of complexity. Futures $\mathbf{3 1}$ (7):721-742.

Keith, D., J. Arqvik, L. Kamookak, J. Ameralik, and the Gjoa Haven Hunters' and Trappers' Organization. 2005. Inuit Qaujimaningit Nanurnut: Inuit knowledge of polar bears. Gjoa Haven Hunters' and Trappers' Organization and Canadian Circumpolar Institute Press, Edmonton, Canada.

Kofinas, G. P. 2005. Caribou hunters and researchers at the co-management interface: emergent dilemmas and the dynamics of legitimacy in power sharing. Anthropologica 47(2):179-196.

Krebs, J. R., and N. B. Davies. 1991. Behavioural ecology: an evolutionary approach. Third edition. Blackwell, Oxford, UK. 
Kulchyski, P., and F. J. Tester. 2007. Kiumajut (talking back): game management and Inuit rights, 1900-70. University of British Columbia Press, Vancouver, Canada.

LaMorte, J. 2001. Risk controls for bear-human conflicts in North American parks: a survey of park practices in bear risk management. Unpublished report to Parks Canada, Lake Louise, Canada.

LegendSeekers Research Inc. 2002. Report on Yukon First Nation elders bear workshop: July 8th, 2002, Whitehorse, Yukon. Parks Canada, Whitehorse, Canada.

Loon, H., and S. Georgette. 1989. Contemporary brown bear use in northwest Alaska. Technical Paper Number 163. Alaska Department of Fish and Game, Kotzebue, Alaska, USA. Available online at: http://www.subsistence.adfg.state.ak.us/TechPap/ tp163.pdf.

MacHutchon, A. G. 1996. Grizzly bear habitat use study, Ivvavik National Park, Yukon: final report. Parks Canada, Inuvik, Canada.

Maraj, R. 2007. Evaluating the consequences of human land use on grizzly bears in southwest Yukon, Canada. Dissertation. University of Calgary, Calgary, Canada.

Mattson, D. J. 1990. Human impacts on bear habitat use. International Conference on Bear Research and Management 8:33-56.

Mattson, D. J., B. M. Blanchard, and R. R. Knight. 1992. Yellowstone grizzly bear mortality, human habituation, and whitebark pine seed crops. Journal of Wildlife Management 56(3):432-442.

Mattson, D. J., S. Herrero, and T. Merrill. 2005. Are black bears a factor in the restoration of North American grizzly bear populations? Ursus 16 (1):11-30.

Mattson, D. J., and T. Merrill. 2002. Extirpations of grizzly bears in the contiguous United States, 1850-2000. Conservation Biology 16(4):1123-1136.

McClellan, C. 1970. The girl who married the bear: a masterpiece of Indian oral tradition. National Museums of Canada, Ottawa, Canada.
McClellan, C. 2001. My old people say: an ethnographic survey of southern Yukon Territory. National Museums of Canada, Ottawa, Canada.

McDonald, M., L. Arragutainaq, and Z. Novalinga. 1997. Voices from the bay: traditional ecological knowledge of Inuit and Cree in the Hudson Bay bioregion. Canadian Arctic Resources Committee and the Municipality of Sanikiluaq, Ottawa and Sanikiluaq, Canada.

McMillan, A. D., and E. Yellowhorn. 2004. First Peoples in Canada. Third edition. Douglas \& McIntyre, Vancouver, Canada.

Morrow, P., and C. Hensel. 1992. Hidden dissension: minority-majority relationships and the use of contested terminology. Arctic Anthropology 29(1):38-53.

Mowat, G., and D. C. Heard. 2006. Major components of grizzly bear diet across North America. Canadian Journal of Zoology $\mathbf{8 4}$ (3):473-489.

Nadasdy, P. 2003. Hunters and bureaucrats: power, knowledge, and aboriginal-state relations in the southwest Yukon. University of British Columbia Press, Vancouver, Canada.

Natcher, D. C., S. Davis, and C. G. Hickey. 2005. Co-management: managing relationships, not resources. Human Organization 64(3):240-250.

National Research Council. 1997. Wolves, bears and their prey in Alaska: biological and social challenges in wildlife management. National Academy Press, Washington, D.C., USA.

Nelson, R. K. 1969. Hunters of the northern ice. University of Chicago Press, Chicago, Illinois, USA.

Nelson, R. K. 1973. Hunters of the northern forest: designs for survival among the Alaskan Kutchin. University of Chicago Press, Chicago, Illinois, USA.

O'Leary, B. L. 1992. Salmon and storage: Southern Tutchone use of an "abundant" resource. Occasional Papers in Archaeology. Government of the Yukon, Whitehorse, Canada. 
Ostrom, E., J. Burger, C. B. Field, R. B. Norgaard, and D. Policansky. 1999. Revisiting the commons: local lessons, global challenges. Science 284:278-282.

Pierotti, R., and D. Wildcat. 2000. Traditional ecological knowledge: the third alternative (commentary). Ecological Applications 10(5):1333-1340.

Rockwell, D. 1991. Giving voice to bear: North American Indian rituals, myths and images of the bear. Roberts Reinhardt Publishers, Niwot, Colorado, USA.

Salmón, E. 2000. Kincentric ecology: Indigenous perceptions of the human-nature relationship. Ecological Applications 10(5):1327-1332.

Sandlos, J. 2007. Hunters at the margin: native people and wildlife conservation in the Northwest Territories. University of British Columbia Press, Vancouver, Canada.

Schullery, P. 2002. Lewis and Clark among the grizzlies: legend and legacy in the American West. First edition. Falcon, Guilford, Connecticut, USA.

Shelton, J. G. 1994. Bear encounter survival guide. Self published, Bella Coola, Canada.

Shepard, P., and B. Sanders. 1985. The sacred paw: the bear in nature, myth and literature. Viking, New York, New York, USA.

Smith, B. L. 1991. Hunt wisely: a guide to maleselective grizzly bear hunting. Yukon Fish and Wildlife Branch, Whitehorse, Canada.

Smith, T. S., S. Herrero, and T. D. DeBruyn. 2005. Alaskan brown bears, humans, and habituation. Ursus 16(1):1-10.

Stringham, S. F., and K. Fredrikkson. 2007. Bear viewing in Alaska: expert techniques for a great adventure. First edition. FalconGuides, Guilford, Connecticut, USA.

Swenson, J. E., F. Sandegren, A. Söderberg, A. Bjärvall, R. Frantzén, and P. Wabakken. 1997. Infanticide caused by hunting of male bears. Nature 386:450-451.
Tanner, A. 1979. Bringing home animals: religious ideology and mode of production of the Mistassini Cree hunters. St. Martin's Press, New York, New York, USA.

Taylor, M., editor. 1994. Density-dependent population regulation of black, brown, and polar bears. Ninth International Conference on Bear Research And Management Monograph Series Number 3.

Treseder, L., J. Honda-McNeil, M. Berkes, F. Berkes, J. Dragon, C. Notzke, T. Schramm, and R. J. Hudson. 1999. Northern Eden: communitybased wildlife management in Canada. International Institute for Environment and Development, London, UK.

Turner, N. J. 2005. The Earth's blanket: traditional teachings for sustainable living. Douglas \& McIntyre, Vancouver, Canada.

Turner, N. J., M. B. Ignace, and R. Ignace. 2000. Traditional ecological knowledge and wisdom of Aboriginal peoples in British Columbia. Ecological Applications 10(5):1275-1287.

Tyrrell, M. 2006. More bears, less bears: Inuit and scientific perceptions of polar bear populations on the west coast of Hudson Bay. Etudes Inuit Studies 30(2): 191-208.

Van Daele, L. J., J. R. Morgart, M. T. Hinkes, S. D. Kovach, J. W. Denton, and R. H. Kaycon. 2001. Grizzlies, Eskimos, and biologists: crosscultural bear management in southwest Alaska. Ursus 12:141-152.

White, G. 2006. Cultures in collision: traditional knowledge and Euro-Canadian governance processes in northern land-claim boards. Arctic 59 (4):401-414.

Wigen, R. J. 2005. History of the vertebrate fauna in Haida Gwaii. Pages 96-115 in D. W. Fedje and R. W. Mathewes, editors. Haida Gwaii: human history and environment from the time of loon to the time of the iron people. University of British Columbia Press, Vancouver, Canada.

Wolfe, R. J. 2006. Playing with fish and other lessons from the North. University of Arizona Press, Tuscon, Arizona, USA. 
Wondrak-Biel, A. 2006. Do (not) feed the bears: the fitful history of wildlife and tourists in Yellowstone. University of Kansas Press, Lawrence, Kansas, USA. 